\title{
Uma experiência do PRONAF "A" no Alto Oeste Potiguar: o assentamento Sítio Coito
}

\author{
An Experience of PRONAF "A" in the Alto Oeste Potiguar: the Site Setting Coito \\ Una Experiencia del PRONAF "A" en Alto Oeste Potiguar: el asentamiento Sitio
Coito
}

\begin{abstract}
Alessandra Holanda do Nascimento ${ }^{1}$ Josué Alencar Bezerra ${ }^{2}$
\end{abstract}

Recebido em 30/11/2016. Aceito em 13/02/2017.

\begin{abstract}
RESUMO: Este trabalho estudou a política do Programa Nacional de Fortalecimento da Agricultura Familiar (PRONAF), especificamente do Grupo "A", estabelecida no assentamento do sítio Coito, localizado no Município de Marcelino Vieira (RN), região do Alto Oeste Potiguar. Para isso, considerando o referido grupo do PRONAF, analisamos o perfil socioeconômico do assentamento do sítio Coito versus a política de aquisição desta linha de crédito, em especial sua influência no cotidiano do agricultor assentado. Para alcançar os propósitos do trabalho, nos apoiamos nas discussões de Azevedo e Pessoa (2011), Azevedo (2012), Fernandes (2004) e Costa (2005). Realizamos entrevistas junto aos representantes da EMATER, com os membros do Sindicato dos Trabalhadores Rurais e na agência do Banco do Nordeste, principal agente financeiro do crédito. Do mesmo modo, realizamos visitas às residências dos assentados do sítio Coito e entrevistas semiabertas. A partir deste estudo, tornou-se possível fazer alguns apontamentos referentes à implantação do PRONAF no espaço rural do município, especialmente no assentamento do sítio Coito, que segue o modelo adotado em todos os assentamentos da região. Consideramos por meio das entrevistas que a atuação do PRONAF "A" na região não tem operado de acordo com os princípios assinalados pelo Programa, pois existem ineficiências que dificultam as metas e objetivos do mesmo. Compreendemos que melhorias necessitam surgir no assentamento de forma que não estejam pautadas somente na produção, procurando investir com mais responsabilidade e coerência na questão social, atuando em problemas como o analfabetismo e a baixa qualificação profissional dos agricultores.
\end{abstract}

Palavras-Chave: Assentamentos Rurais. PRONAF "A". Sítio Coito. Marcelino Vieira (RN).

ABSTRACT: This work studied the policy of the National Program for Strengthening Family Agriculture (PRONAF), specifically Group "A", established at the Coito Site, located in the municipality of Marcelino Vieira (RN), Alto Oeste Potiguar region. In order to do so, considering the aforementioned PRONAF group, we analysed the socioeconomic profile of the Coito Site settlement versus the policy of acquiring this line of credit, especially its influence on the daily lives of the settled farmers. In order to reach the goals of the work, we rely on the discussions of Azevedo and Pessoa (2011), Azevedo (2012), Fernandes (2004) and Costa (2005). We conducted interviews with representatives of EMATER, the Rural Workers' Union and the head office of Banco do Nordeste, the main credit agent. In the same way, we made visits to the homes of the settlers of the Coito site, semiopen interviews. From this study, it became possible to make some notes regarding the implementation of PRONAF in the rural area of the municipality, especially in the settlement of the Coito Site, which follows the model adopted in all settlements in the region. We consider through the interviews that PRONAF "A" performance in the region has not operated according to the principles indicated by the Program, as there are inefficiencies that hamper its goals and objectives. We understand that improvements need to arise in the settlement, so that they are not only based on 
production, seeking to invest with more responsibility and coherence in the social issue, acting on problems such as illiteracy and poor professional qualification of farmers.

Key Words: Rural Settlements. PRONAF "A". Coito Site. Marcelino Vieira (RN).

RESUMEN: Este trabajo estudió la política del Programa Nacional de Fortalecimiento de la Agricultura Familiar (PRONAF), específicamente del Grupo "A", establecida en el asentamiento del sitio Coito, ubicado en el Municipio de Marcelino Vieira (RN), región del Alto Oeste Potiguar. Para ello, considerando el referido grupo del PRONAF, analizamos el perfil socioeconómico del asentamiento del sitio Coito versus la política de adquisición de esta línea de crédito, en especial su influencia en el cotidiano del agricultor asentado. Para alcanzar los propósitos del trabajo, nos apoyamos en las discusiones de Azevedo y Pessoa (2011), Azevedo (2012), Fernandes (2004) y Costa (2005). Se realizaron entrevistas a los representantes de EMATER, con los miembros del Sindicato de los Trabajadores Rurales y en la agencia del Banco del Nordeste, principal agente financiero del crédito. Del mismo modo, realizamos visitas a las residencias de los asentados del sitio Coito y entrevistas semiabiertas. A partir de este estudio, se hizo posible hacer algunos apuntes referentes a la implantación del PRONAF en el espacio rural del municipio, especialmente en el asentamiento del sitio Coito, que sigue el modelo adoptado en todos los asentamientos de la región. Consideramos por medio de las entrevistas que la actuación del PRONAF "A" en la región no ha operado de acuerdo con los principios señalados por el Programa, pues existen ineficiencias que dificultan las metas y objetivos del mismo. Comprendemos que las mejoras necesitan surgir en el asentamiento de forma que no estén pautadas solamente en la producción, buscando invertir con más responsabilidad y coherencia en la cuestión social, actuando en problemas como el analfabetismo y la baja cualificación profesional de los agricultores.

Palabras Clave: Asentamientos Rurales. PRONAF "A". Sitio Coito. Marcelino Vieira (RN).

\section{INTRODUÇÃO}

Neste trabalho estudamos a atuação do Programa Nacional de Fortalecimento da Agricultura Familiar (PRONAF), dando destaque ao Grupo "A", que se destina à aquisição de crédito por parte de agricultores assentados pela reforma agrária. Para isso, procuramos entender a realidade vivida pelos assentados da Comunidade Agrícola do sítio Coito, localizada no município de Marcelino Vieira (RN), como parâmetro para entender a atuação do acesso ao crédito desta modalidade do programa no Alto Oeste Potiguar. Estes sítios, que associamos à definição de aglomerados rurais (IBGE, 2015), abrigam um número pequeno de moradores, mas que em seu conjunto, torna-se representativo para o total da população municipal. Neste espaço, investigamos a aplicabilidade do PRONAF "A" no município e a relação com a qualidade de vida dos assentados, tendo como referência a aquisição desta linha de crédito.

Para tanto, este trabalho esteve pautado na dimensão de um pequeno município do Alto Oeste Potiguar que, segundo o Banco do Nordeste (BNB), obteve 18 acessos do PRONAF "A" no ano de 2013, e que apresentou este município como um dos mais beneficiados, ressaltando que, nos anos anteriores e posteriores à 2013, não houveram acessos a esta linha de crédito no respectivo banco. As principais comunidades identificadas no âmbito do município de Marcelino Vieira são os sítios Coito, Pitombeira, Salgadinho e Passagem de Pedra, aglomerados rurais que abrigam 40,8\% da população 
total do município (3.371 habitantes). A comunidade selecionada para a realização desta pesquisa foi a do sítio Coito, tendo em vista ser esta comunidade a que abriga o maior assentamento de reforma agrária no município, com 10 famílias. Os demais assentamentos são menores em dimensão, contendo, respectivamente, uma quantidade menor de beneficiários. De acordo com o INCRA, um assentamento rural é um conjunto de unidades agrícolas independentes entre si, instaladas em propriedades que originalmente pertencia a um único proprietário. Cada uma dessas unidades, chamadas de parcelas, lotes ou glebas, é entregue a uma família. A quantidade de glebas num assentamento depende da capacidade da terra de comportar e sustentar as famílias assentadas. O tamanho e a localização de cada lote são determinados pela geografia do terreno e pelas condições produtivas que o local oferece.

Este assentamento é gerenciado pela Secretaria de Estado de Assuntos Fundiários e Apoio a Reforma Agrária do Rio Grande do Norte (SEARA-RN) e não pelo Instituto de Colonização e Reforma Agrária (INCRA). Apesar disso, o assentamento do sítio Coito também faz parte do Programa Nacional de Crédito Fundiário (PNCF), que se enquadra dentro da Secretaria de Reordenamento Agrário (SRA), vinculada ao Ministério de Desenvolvimento Agrário (MDA).

Como etapa da pesquisa, realizamos visitas na Empresa de Assistência Técnica e Extensão Rural (EMATER) e no Sindicato dos Trabalhadores Rurais de Marcelino Vieira, além de coletar dados na agência do Banco do Nordeste, localizado no município de Pau dos Ferros $(\mathrm{RN})$. Concomitantemente, visitamos as residências dos assentados da comunidade do sítio Coito, onde realizamos entrevistas semiabertas, compostas por questões objetivas e subjetivas, pautando investigar os rebatimentos do PRONAF "A" no perfil socioeconômico das famílias assentadas. Posteriormente, de acordo com as informações e dados coletados, elaboramos mapas representativos da localização geográfica dos assentamentos rurais no município de Marcelino Vieira, bem como a espacialização do PRONAF "A" no Alto Oeste Potiguar, região que reúne as três microrregiões geográficas do IBGE (Pau dos Ferros, São Miguel e Umarizal), que compreende 37 municípios distribuídos em uma área de 5.265,577 quilômetros quadrados (IBGE, 1990, 2011). Nesse percurso, pudemos entender que a realidade vivida pelos assentados não condiz com os princípios assinalados pelos objetivos do PRONAF.

\section{O PRONAF: ORIGEM, CONCEPÇÕES E GRUPOS DE CRÉDITO}

Criado pelo Governo Federal no ano de 1996, a partir do Decreto № 1.946 e atualmente sob gestão do MDA, o PRONAF tem evidenciado reconhecimento por parte do setor público aos agricultores. De acordo com Shchneider, Mattei e Cazella (2004), o Programa busca fortalecimento da agricultura familiar, mediante ajuda técnica e financeira, e 
Uma experiência do PRONAF "A" no Alto Oeste Potiguar: o assentamento Sítio Coito

contribuir para a geração de desenvolvimento rural sustentável. Busca-se, ainda, fortalecer a aptidão produtiva da agricultura familiar, bem como colaborar para a geração de emprego e renda nas áreas rurais e aquilatar a qualidade de vida dos agricultores familiares. Para isso, quatro objetivos específicos completam o escopo do programa: a) ajustar as políticas públicas de acordo com a realidade dos agricultores familiares; b) viabilizar a infraestrutura necessária à melhoria da atuação produtiva dos agricultores familiares; c) abranger o nível de profissionalização dos agricultores familiares, através do acesso aos novos padrões de tecnologia e de gestão social; d) instigar o acesso desses agricultores aos mercados de insumos e produtos.

Partindo do pressuposto de que o PRONAF faz parte do conjunto de políticas públicas voltadas para o setor rural brasileiro de baixa renda, em especial para os agricultores familiares, entendemos a importância de assinalar que é por intermédio da ação da Secretaria de Agricultura Familiar, que o respectivo Programa é posto em prática. Para que possamos compreender melhor sua organização na divisão do MDA, a figura 01 nos indica sua posição juntamente com as demais secretarias.

Figura 01. Organograma da Estrutura Institucional do MDA

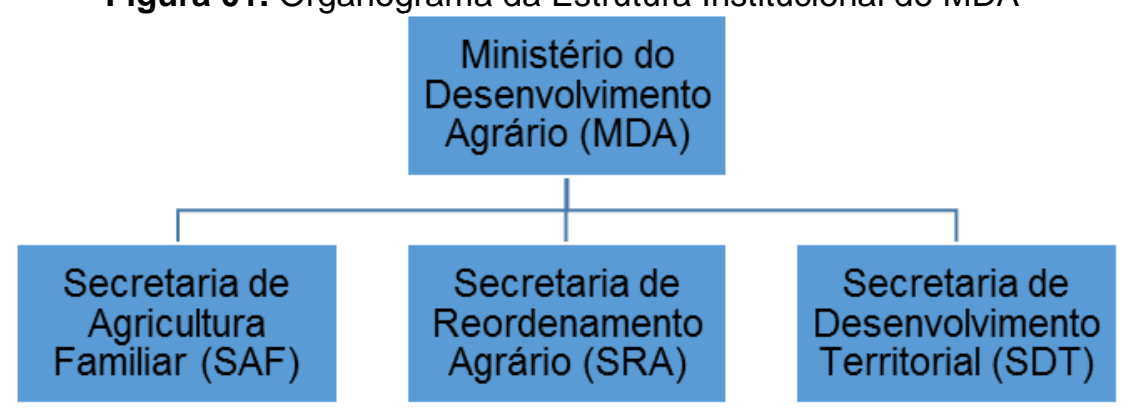

Fonte: MDA,2015. Elaboração dos autores.

As três secretarias existentes exercem funções distintas no MDA, sendo que a SAF possui a missão de consolidar a agricultura familiar, buscando promover o desenvolvimento rural. Nesta secretaria, se encontra o PRONAF. A SRA atua na implementação de políticas públicas para o meio rural brasileiro, promovendo ações complementares à reforma agrária, se enquadrando, nesse caso, o acesso a terra pelo Programa Nacional de Crédito Fundiário (PNCF). Por último, a SDT busca colaborar para o desenvolvimento territorial entre os agricultores familiares e beneficiários da reforma e do reordenamento agrário (MDA, 2015).

Segundo Shchneider, Mattei e Cazella (2004), o PRONAF está organizado dentro do contexto da agricultura familiar, de acordo com as características da propriedade rural, dividido em seis categorias distintas que se aplicam nos grupos $A, B, C, A / C, D$ e $E$. 
- Grupo A: engloba os assentados da reforma agrária no Programa Nacional de Reforma Agrária (PNRA), do Programa Nacional de Crédito Fundiário (PNCF), além de abarcar os reassentados devido à construção de barragens, podendo ou não financiar atividades agropecuárias;

- Grupo B: agricultores familiares e remanescentes de quilombos, indígenas e trabalhadores rurais com renda bruta anual de até $R \$ 2.000,00$;

- Grupo C: agricultores familiares com renda bruta anual entre $R \$ 2.000,00$ a $R \$$ 14.000,00, que apresentem explorações intermediárias com bom potencial de resposta produtiva;

- Grupo A/C: também inclui os agricultores assentados do PNRA e do PNCF, bem como agricultores de reservas extrativistas; o beneficiamento deve ser voltado para as atividades agropecuárias bem como para industrialização da produção;

- Grupo D: agricultores estabilizados economicamente com renda bruta anual entre $R \$ 14.000,00$ e $R \$ 40.000,00$;

- $\quad$ Grupo E: agricultores com renda bruta anual entre $\mathrm{R} \$ 40.000,00$ a $\mathrm{R} \$ 60.000,00$.

Sobre o Programa, Azevedo e Pessoa (2011) afirmam que o PRONAF abrange agricultores familiares na qualidade de posseiros, arrendatários, parceiros, meeiros, concessionários de terras públicas, assentados e proprietários de terras que utilizam preferencialmente mão de obra familiar durante o processo produtivo, podendo utilizar até dois empregados permanentes.

De acordo com Azevedo (2012), este programa vem sendo visto como uma das mais importantes políticas públicas que atuam sobre o meio rural brasileiro. Isso acontece porque até o início dos anos de 1990 não existiam políticas públicas específicas que atuassem diretamente com o público relacionado à agricultura familiar. Essa importância se dá devido o PRONAF estar presente em grande parte dos municípios brasileiros e, de acordo com o discurso do próprio MDA, o Programa contribui para as transformações e avanços no espaço agrário nacional, possibilitando uma maior democratização do acesso ao crédito e a visibilidade social de agricultores que, até então, eram vistos como pobres e miseráveis e que enfrentavam restrições para adquirir recursos financeiros. Entretanto, será que esses avanços e transformações aconteceram de fato? Na prática, como podemos identificar os rebatimentos da ação do Programa entre os agricultores familiares? E, mais particularmente, na vida dos assentados do sítio Coito? Tendo estas inquietações como campo de orientação para pensarmos a realidade posta em investigação, atuando como impulsionadoras para a realização da pesquisa, procuramos estudar a comunidade rural em pauta, quais os 
Uma experiência do PRONAF "A" no Alto Oeste Potiguar: o assentamento Sítio Coito

benefícios e limitações, bem como as potencialidades e fragilidades, na atuação local do Programa.

\section{AGRICULTOR FAMILIAR OU AGRICULTOR CAMPONÊS: QUEM SÃO ESSES SUJEITOS NO CONTEXTO DO PRONAF?}

A ideia de "Novo Mundo Rural", criado no Governo de Fernando Henrique Cardoso (FHC), entre 1995-2002, se aportava da noção de desenvolvimento "sustentável", procurando mercantilizar a questão agrária, colocando-a, deste modo, no território do capital, e os camponeses inteiramente subordinados. Com isso, contribuiu-se para o surgimento do termo "agricultor familiar", na tentativa de substituir a nomenclatura "agricultor camponês", que se estabeleceu como um conceito aceito entre aqueles que estudam a realidade, tanto pelos estudiosos do tema, como entre os sujeitos sociais organizados em movimentos sociais como, por exemplo, o Movimento dos Pequenos Agricultores (MPA) e o Movimento dos Trabalhadores Rurais Sem Terra (MST). A partir desse período, o modo de vida camponês, a cultura produtiva e a questão sociopolítica passaram a ser colocadas com mais frequência em discussão. Segundo Fernandes (2004, p. 20, grifo do autor),

O governo adotou nova tese e criou um "novo mundo rural", onde a agricultura camponesa é metamorfoseada em agricultura familiar, procurando convencer os trabalhadores de que o mundo mudou e que a luta pela terra é coisa do passado; que a subalternidade é "natural", na "integração ao capital e ao mercado".

A partir da existência dessa nova conceituação, o termo "camponês" vai sendo substituído por "agricultor familiar", que passa a ser entendido como uma representação do "novo" e do "moderno" no meio rural brasileiro. Dessa forma, vê-se que o agricultor familiar deve se integrar ao mercado consumidor capitalista; enquanto que o camponês passou a ser concebido, política e imageticamente, dentro de uma visão atrasada e arcaica das atividades realizadas no campo (FERNANDES, 2004). De maneira geral, entende-se que a agricultura familiar se caracteriza pelo trabalho realizado em prol da própria família que, por sua vez, possui uma porção de terra a ser cultivada. Os trabalhos conduzidos na terra realizam-se pelos membros da família, ou seja, pelos cônjuges e filhos, que, por vezes, recebem ajuda de outros parentes próximos. No entanto, Wanderley (2003, p. 43-44, grifo do autor) nos auxilia nesta compreensão, quando diz que:

Para uns, o conceito agricultura familiar se confunde com a definição operacional adotada pelo PRONAF que propõe uma tipologia de beneficiários em função de sua capacidade de atendimento. Para outros, agricultura familiar corresponde a uma certa camada de agricultores, 
capazes de se adaptar as modernas exigências do mercado em oposição aos demais "pequenos produtores" incapazes de assimilar tais modificações.

Com isso, entendemos que os agricultores que não conseguem assimilar as modificações e a modernização na agricultura são os chamados camponeses; enquanto que os agricultores familiares seriam aqueles que conseguiram se modernizar e dinamizar suas atividades agrícolas, se inserindo no mercado capitalista. Todavia, essa diferença de conceituação é muito complexa, abarcando inúmeras discussões que, como afirma Felício (2006. p. 16 a 17),

Trata-se de estudar, discutir e compreender as relações sujeito-espaço analisando as ações dos dois sujeitos: o camponês e o agricultor familiar. As Ciências Humanas não conseguiram delinear ainda, de forma satisfatória, as diferenças entre eles. O problema que se coloca não é só a diferença entre esses dois sujeitos (se é que existe), mas o modo como sua existência, como horizonte pode ser entendido. Em outras palavras, qual o papel e o lugar dos camponeses na sociedade capitalista?

Desse modo, entendemos que a diferenciação desses conceitos não se dá pelos tipos de sujeitos em questão, mas sim pelas distintas relações que cada um possui com o espaço e o território. Nessa perspectiva, no que se alude ao questionamento feito sobre o lugar que os camponeses assumem na sociedade capitalista, constata-se que estes só estarão de fato inseridos no espaço agrário se estabelecerem uma ligação efetiva com a macroestrutura do capitalismo.

Nesse contexto, levando em consideração o temário que pretende discutir a respeito do que representam ou constituem as denominadas políticas públicas, ou seja, o que entendemos por políticas públicas, há de se buscar entender sua relação com as ações para a sociedade.

$\mathrm{Na}$ busca de uma definição que estabeleça o que são políticas públicas, Teixeira (2002, p.2) coloca que "Políticas públicas são diretrizes, princípios norteadores de ação do poder público; regras e procedimentos para as relações entre poder público e sociedade, mediações entre atores da sociedade e do Estado".

No propósito de entender a importância das políticas públicas e da ação política, Sousa e Fonseca (2012, p.2) interpõem que:

As políticas públicas são de suma importância para o movimento emergente de uma determinada região. A falta dessas políticas dificulta a fixação do homem no seu meio, levando-os assim ao êxodo rural e a elevação da população nas grandes cidades, acentuando com isso o problema social urbano. 
Uma experiência do PRONAF "A" no Alto Oeste Potiguar: o assentamento Sítio Coito

Desse modo, a presença das políticas públicas pode contribuir com a população rural, de forma que, entre as mudanças ocorridas, podemos citar, por exemplo, o maior acesso à eletrificação e à iluminação elétrica das residências; a obtenção de alternativas de transporte automotivo, principalmente motocicletas, para a locomoção do campo para a cidade; a aquisição de bens de consumo duráveis, como os eletrodomésticos e os implementos agrícolas, bem como o acesso à água encanada e/ou à cisternas de placa. Pode-se dizer que os aspectos acima citados estão intimamente ligados a outros pontos, como a melhoria na qualidade das instalações físicas das casas, uma vez que as condições habitacionais também progrediram significativamente.

Dentre as principais dificuldades encontradas pela população rural, em especial os assentados do sítio Coito, podemos vincular o acesso inexistente aos serviços básicos de saúde e educação. Na questão da saúde, por exemplo, as condições de assistência médica são muito precárias, uma vez que não existe posto de saúde próximo para atendimento básico, como serviços médicos e odontológicos. Já na área da educação há alguns problemas estruturais, entre eles a falta de segurança dos alunos ao irem para a escola, uma vez que o município de Marcelino Vieira ainda transporta os estudantes em caminhões Pau de Arara, transporte irregular, geralmente compreendido por caminhonetes ou caminhões, dotados com varas longitudinais na carroceria, sobre as quais se estende apenas uma lona como cobertura sem o mínimo de segurança. Isso acontece porque os ônibus cedidos pelo Programa Caminho da Escola, do Governo Federal, ainda não são suficientes para a demanda de alunos residentes na zona rural. Conquanto, devemos dar relevância ao fato de que, problemas como estes não são de competência direta do PRONAF para resolvê-los, mas são variantes que dificultam a permanência do agricultor no campo.

Haja vista os problemas supracitados nos questionamos porque problemas como esses não são resolvidos. Qual a intenção de fazer com que os agricultores permaneçam na situação de pobres e coitados? Para tanto, Azevedo (2012, p. 155) defende que:

Portanto, mantêm-se e reproduz-se o sistema de relações que garante a contiguidade de agentes e grupos no exercício do poder público e em algumas atividades de prestação de serviços públicos, enquanto isso, os problemas e a precariedade no tocante à assistência rural se mantêm.

Em linhas gerais, entendemos que o PRONAF tem favorecido a vida do agricultor e contribuído de algum modo para a permanência dessa população no meio rural. No entanto, essa atuação ainda não é suficiente, pois se necessita fazer muito mais para melhorar, não só quantitativamente, mas principalmente qualitativamente, a vida desses agricultores. 


\section{UMA BREVE LEITURA SOBRE OS ASSENTAMENTOS RURAIS NO RIO GRANDE DO NORTE}

Atualmente, vemos que o acesso à terra no Brasil vem se configurando como um assunto de discussões teórico-conceituais e de reflexões críticas, principalmente porque a reforma agrária é um dos vários elementos que estão inseridos na questão fundiária brasileira. Ao entender a reforma agrária como uma política pública de caráter institucional, na qual o Estado é o responsável pela construção e o acompanhamento de tais políticas, pretende-se compreender o contexto de surgimento dos assentamentos rurais, sem nos aprofundarmos nas diversas nuances que compõe a questão agrária brasileira.

Segundo Costa (2005), nos faz necessário mostrar que os assentamentos rurais podem ser classificados em cinco tipos: I - projetos de colonização; II - reassentamento de populações atingidas por barragens de usinas hidrelétricas; III - planos estaduais de valorização de terras públicas e de regularização possessória; IV - criação de reservas extrativas e outras atividades relacionadas ao aproveitamento de recursos naturais renováveis; e V - programas de reforma agrária via desapropriação por interesse social, que são os que prevalecem no estado do Rio Grande do Norte, sendo este último o enquadrado pelo Sítio Coito, apesar deste não ser um assentamento do INCRA.

Até o momento, o que se observa a respeito da realização efetiva da reforma agrária brasileira é o fato de que esta vem acontecendo, geralmente, através de uma mera distribuição de terras.

Estudiosos como Fernandes (1999) afirmam que, no Brasil, não existe um verdadeiro e eficaz processo de reforma agrária, o que existe é uma política de assentamentos rurais. Isso acontece porque se coloca em prática uma política de assentamentos, o que apresentará resultados em menor tempo do que planejar e acompanhar um processo de reforma agrária. De acordo com o contexto atual da reforma agrária, representado pelo INCRA, podemos compreender que o Estado se apresenta como o principal comprador de terras, pagando, na maioria dos casos, um preço superior ao do mercado. Para complementar, Fernandes (1999, p.227), escreve que:

Frente a essa realidade, a reforma agrária é deturpada e, lentamente, cresce a perspectiva de uma reforma imobiliária. Assim, alguns latifundiários chegam mesmo a incentivar as ocupações, garantindo a infraestrutura como forma de agilizar a desapropriação. Desse modo, a expropriação é pervertidamente convertida em ato de compra e venda, o que chamamos aqui de mercantilização da expropriação e da desapropriação da terra. Além de concentrar e reter especulativamente a terra, latifundiários no Brasil ainda sonegam os impostos incidentes sobre elas.

Torna-se importante ressaltar que, segundo Costa (2005), o Rio Grande do Norte tem passado por um processo de criação de assentamentos rurais nos últimos anos, 
Uma experiência do PRONAF "A" no Alto Oeste Potiguar: o assentamento Sítio Coito

sobretudo a partir de 1995, embora este processo de criação de assentamentos ainda tenha se mostrado de forma bastante elementar, uma vez que não foi capaz de gerar intensas modificações na estrutura fundiária do estado. O aumento que houve na quantidade de assentamentos no estado foi impulsionado pelo processo de intensificação da luta pela terra em todo o Brasil, liderada pelos movimentos sociais rurais, como o MST.

Sobre o tema, Costa (2005) destaca que entre os motivos que geraram desapropriações no estado, contribuindo para a criação de assentamentos, um foi a crise agropecuária que estava ligada à ocorrência de grandes secas e/ou períodos de estiagem, o que tornava, dessa forma, mais vantajoso para alguns fazendeiros fazerem a comercialização de suas propriedades para o Estado que, por sua vez, as utilizariam para fins de reforma agrária. Os fazendeiros vendiam suas terras para o Estado, visando as altas indenizações que eram pagas pelo INCRA, supervalorizando suas terras.

Para entender melhor a espacialização dos assentamentos pelo Rio Grande do Norte, destacamos que, até o ano de 2002, a Microrregião de Mossoró apresentava a maior concentração de assentamentos (39 no total), seguida de outras Microrregiões, como: Chapada do Apodi (30 assentamentos), Baixa Verde (29 assentamentos), Litoral Nordeste (25 assentamentos) e Vale do Açu (23 assentamentos). Uma possível justificativa para a forte existência de assentamentos nessas áreas se refere às questões históricas e fisiográficas da região, com a difusão das principais lavouras de produção agrícola do estado e pela forte presença de empresas do setor do agronegócio moderno no Vale do Açú e Região de Mossoró.

Em contrapartida, as Microrregiões de Pau dos Ferros (um assentamento no município de Itaú), Seridó Oriental (um assentamento no município de São José do Seridó) e Umarizal (um assentamento no próprio município de Umarizal) apresentavam, até o ano de 2002, números bem inferiores, se comparados ao conjunto de assentamentos rurais existentes nas Microrregiões de Apodi, Mossoró, Baixa Verde, Litoral Nordeste e Vale do Açu. Nesse caso, Costa (2005) destaca dois principais motivos que dificultam o surgimento de assentamentos nessas áreas, que é a localização em áreas que sofrem constantemente com a seca e suas respectivas adversidades climáticas aliadas a uma menor atuação dos movimentos sociais de luta pela terra.

Segundo o Ministério do Desenvolvimento Agrário (MDA), o principal programa de crédito, o Programa Nacional de Fortalecimento da Agricultura Familiar (PRONAF), que beneficia agricultores familiares e assentados da reforma agrária, compreendeu, nos últimos anos (2004-2015), no território do Alto Oeste $^{3}$, mais de 180 milhões em crédito, que passam pelas instituições financeiras até chegar ao pequeno agricultor. 
Para que se possa entender melhor, os dados disponibilizados pelo Banco do Nordeste (BNB), sediado na cidade de Pau dos Ferros, indicam que, até o ano de 2013, 16 municípios inseridos no Alto Oeste Potiguar acessaram crédito do PRONAF "A", totalizando 297 operações, assim como mostra a figura 02, a seguir.

No mapa representado acima podemos entender a distribuição espacial dos municípios do Alto Oeste Potiguar que acessaram o crédito do PRONAF "A" até o ano de 2013. Esses dados afirmam que a quantidade de assentamentos na região do Alto Oeste Potiguar cresceu consideravelmente, sendo que, até o ano de 2002, a Microrregião de Pau dos Ferros possuía apenas um assentamento, localizado no município de Itaú; diferentemente da realidade observada atualmente. De acordo com dados cedidos pelo Banco do Nordeste (BNB), municípios como: Riacho de Santana (44 operações), Encanto (36 operações), Portalegre (33 operações), Doutor Severiano (28 operações) e Coronel João Pessoa (28 operações) merecem importante destaque na quantidade de acessos e possivelmente no surgimento de novos assentamentos rurais. De acordo com os mesmo dados, o PRONAF A tem financiado os assentamentos nos municípios de Marcelino Vieira, atendendo os objetivos do PNCF.

Figura 02. Alto Oeste Potiguar: número de acesso ao crédito do PRONAF "A"

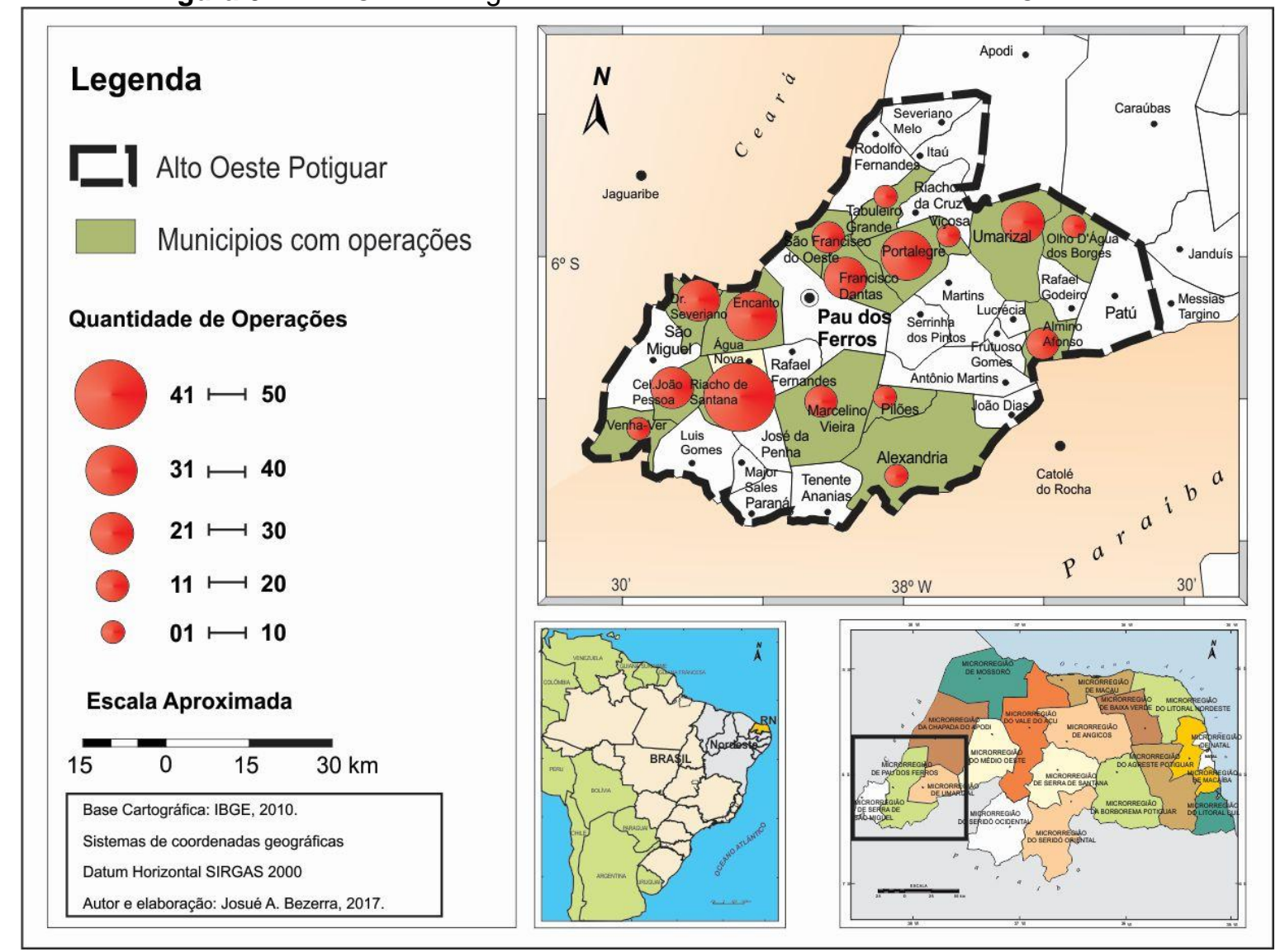

Fonte: dados extraídos na agência do Banco do Nordeste, em Pau dos Ferros (RN), principal agente financeiro da região. Elaboração de Josué A. Bezerra, 2017. 
Mesmo diante do referido crescimento na quantidade de assentamentos no Alto Oeste Potiguar, devemos destacar que esse quantitativo ainda permanece inferior à quantidade de assentamentos existentes em outras regiões do estado, dando destaque as Microrregiões de Mossoró e da Chapada do Apodi.

Dessa forma, queremos evidenciar que a existência dos assentamentos aliada a condições mínimas de sobrevivência e de produção são de extrema importância para que o agricultor se fixe de fato no campo, uma vez que ele necessita se sustentar financeiramente, mesmo diante de problemas como, por exemplo, a prática da agricultura de sequeiro do qual a região Nordeste sofre frequentemente com a escassez de chuvas, o que dificulta a produção agrícola, caso não se recorra à técnica da irrigação.

Logo, percebemos que o foco da atual política de reforma agrária não se baseia no surgimento e/ou fortalecimento das potencialidades dos assentamentos, tampouco através de elementos essenciais como a assistência técnica, que auxilie o produtor na hora de definir o quê, como e quando produzir. Contudo, as melhorias que necessitam surgir não devem estar pautadas exclusivamente na produção, uma vez que se deve investir na questão social, implementando políticas, planos e programas governamentais que atuem em problemas como o analfabetismo e a baixa qualificação profissional dos agricultores assentados, o que, por sua vez, poderia gerar um aumento na renda da família, além de conhecer e passar a ter maior cuidado com a natureza e seus recursos.

O que podemos afirmar é que os recursos utilizados por estas linhas de crédito movimentam o setor produtivo regional e, em particular, as pequenas cidades, onde se encontram as principais lojas de insumos agrícolas da região, e também um conjunto de atividades e serviços voltados para estruturação dos espaços destes pequenos produtores.

\section{O MUNICÍPIO DE MARCELINO VIEIRA (RN) E O ASSENTAMENTO DO SÍTIO COITO: CARACTERIZANDO O TERRITÓRIO E O PRONAF}

O município de Marcelino Vieira se encontra na porção Oeste Potiguar, distanciandose aproximadamente 415 quilômetros da capital do estado, Natal. Segundo o Instituto Brasileiro de Geografia e Estatística (IBGE, 2010), o município de Marcelino Vieira apresenta uma população de 8.265 habitantes, sendo, deste total, 4.894 habitantes residentes na zona urbana e 3.371 habitantes residentes na zona rural.

De acordo com as informações cedidas pela Empresa de Assistência Técnica e Extensão Rural (EMATER), o município de Marcelino Vieira possui a totalidade de oito assentamentos localizados em distintas comunidades rurais (figura 03), que são respectivamente: I - Sítio Juazeiro, II - Sítio Água Branca, III - Sítio Varzinha, IV - Sítio 
Pitombeira, V - Sítio Coito, VI - Sítio Pacatuba, VII - Sítio Passagem de Pedra e VIII - Sítio Salgadinho.

Deste modo, necessitamos esclarecer que desses oito assentamentos, apenas quatro destes foram financiados pelo PRONAF "A". Os demais estão, até o momento, apenas sob o financiamento do PNCF. De acordo com a principal instituição financeira responsável pelo crédito na região, o Banco do Nordeste, a linha de crédito disponibilizado para essa modalidade oferece até 25 mil reais por agricultor, em até três operações. Esse valor poderá ser elevado para $R \$ 26.500,00$ quando contemplar verba para assistência técnica, com juros de $0,5 \%$ ao ano.

Nesta perspectiva, o assentamento do Sítio Coito se destaca por possuir o maior número de financiamentos coletivos do município, abrangendo o total de 10 famílias. Este assentamento, assim como os demais, é gerenciado pela SEARA-RN, que é uma Secretaria do Governo do Estado que atende prioritariamente os pequenos e médios agricultores, promovendo o acesso a terra, regularização fundiária e apoio à reforma agrária. Além disso, desenvolve ações complementares à reforma agrária e implanta políticas públicas que possibilitem o acesso, o uso, a permanência e a legitimidade da terra.

Figura 03. Mapa de acesso às comunidades em Marcelino Vieira

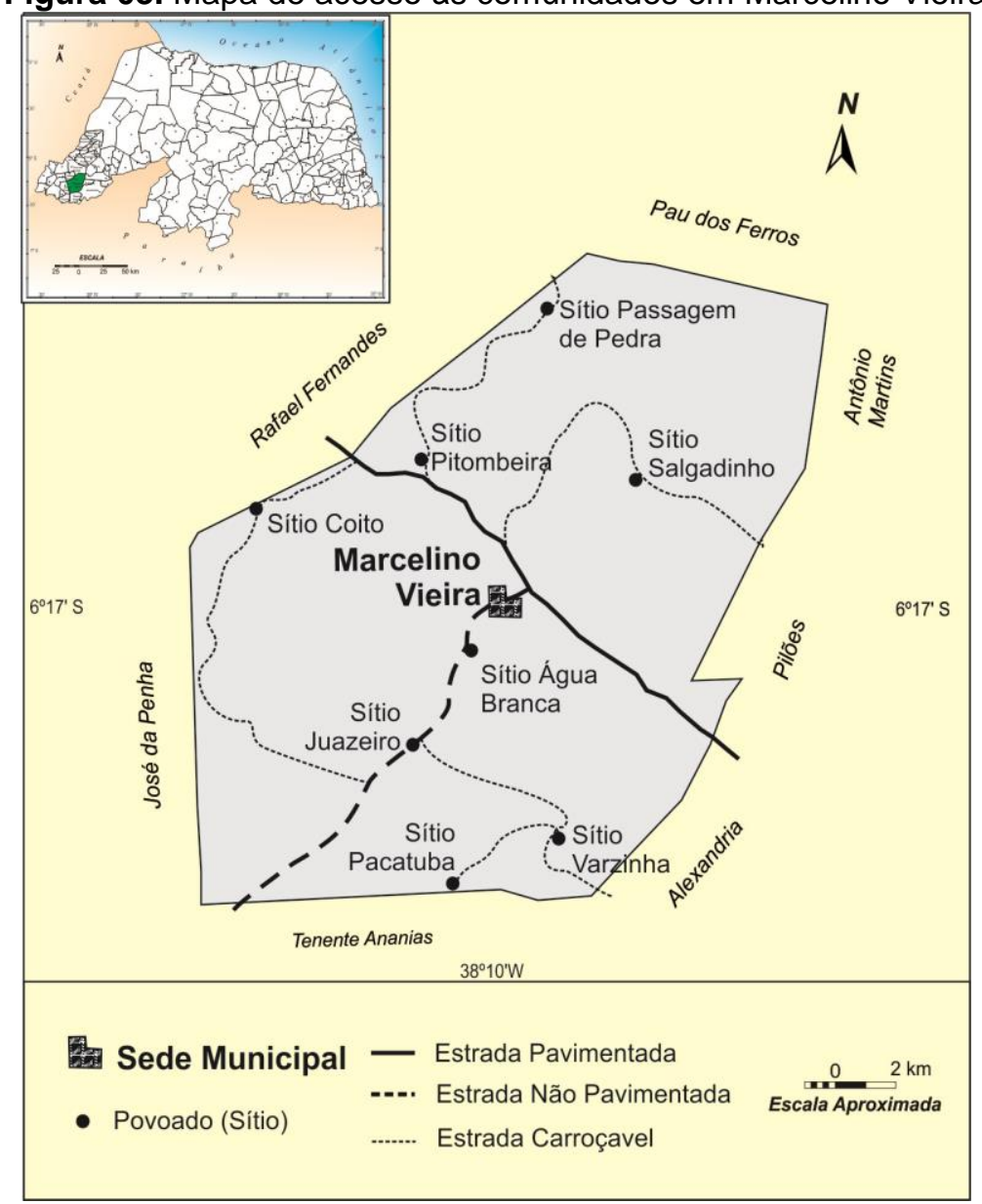

Fonte: IDEMA, 2014. Adaptado pelos autores (ago., 2015). Elaboração de Josué A. Bezerra, 2016. 
Uma experiência do PRONAF "A" no Alto Oeste Potiguar: o assentamento Sítio Coito

Este assentamento foi fundado no ano de 2006, através do PNCF, em que todos os investimentos são gerenciados pela própria comunidade, podendo contribuir tanto para a compra de terras, como para o aumento da produção ou, ainda, para projetos que beneficiem a comunidade e que possam trazer desenvolvimento local.

No ano de 2013, os agricultores dessa comunidade recorreram a aquisição de crédito pelo PRONAF "A", através de empréstimos/projetos coletivos, em busca de implementar a produção agrícola, bem como a criação de gado.

Conforme a pesquisa realizada entre os dias 09 e 11 de maio de 2015, junto aos agricultores assentados dessa comunidade, inicialmente constatamos que dos nove entrevistados, quatro deles possuem uma renda inferior a um salário mínimo, mantendo-se, desta forma, dependentes do Programa Bolsa Família e dos poucos lucros gerados pela agricultura, enquanto que os demais, totalizando cinco entrevistados, possuem sua renda pautada na aposentadoria, e são os titulares dos lotes e participam das atividades nos mesmos.

No que se refere à contribuição dos membros da família na produção, identificamos que apenas quatro alegaram receber ajuda de algum familiar nas atividades desenvolvidas no campo, destacamos o auxílio dos filhos e das respectivas esposas.

Quando questionados sobre o fato de residirem ou não no assentamento, contatamos que seis deles alegam que não moram neste por diversos motivos, dentre estes, destacamos: a dificuldade de acesso e a longa distância da sede do município, a inexistência de escolas e de posto de saúde próximos e a falta de emprego e renda na zona rural. Os agricultores se revezam no deslocamento até os lotes, mesmo não atendendo as diretrizes de criação do assentamento no que se refere ao residir no local. No âmbito da produção, cinco entrevistados afirmaram que sua produção permaneceu igual, mesmo após a aquisição de crédito do PRONAF, pois independentemente de seca, a produção sempre foi pequena. Na sequência, estão os três beneficiários que afirmam ter diminuído bastante a produção, girando em torno de $60 \%$. Isso aconteceu, segundo os entrevistados, devido aos últimos anos terem sido de grande estiagem na região, fato que diminuiu a produção em mais da metade. Em contrapartida, apenas um entrevistado expôs que sua produção aumentou, embora que, de maneira muito incipiente (cerca de $3 \%$ ). Desta maneira, constatamos que a quantidade da produção que foi obtida nos últimos anos, de 2013 a 2015, manteve-se basicamente igual ou inferior, pois, de acordo com as justificativas elencadas pelos entrevistados, os quatro últimos anos de seca foram determinantes para a diminuição intensa da produção.

Sendo assim, aproveitamos para adentrar em outro ponto que está ligado a este. Registramos, por meio das informações adquiridas nas entrevistas, de que os principais 
produtos produzidos pela comunidade são: o feijão e o milho, seguidos da cana-de-açúcar e do sorgo. Estes dois últimos são utilizados para a alimentação do gado. Contudo, percebemos que, atualmente, a produção se destina integralmente para o consumo familiar. Isso acontece porque a produção não está sendo suficiente para o consumo da família e muito menos para a comercialização, embora devamos ressaltar que há alguns anos, quando as safras eram maiores, uma parte da produção era vendida, em sua maioria, para pequenos comerciantes locais, donos de mercearias e de supermercados na sede do município de Marcelino Vieira.

A partir disso, quando essa comercialização acontecia, os pequenos lucros eram investidos prioritariamente na manutenção da unidade familiar, na alimentação e/ou destinada ao pagamento da conta de energia elétrica. Quando o lucro era maior, se compravam utensílios domésticos e implementos agrícolas.

Um dos entrevistados destacou que houve um período em que a sua produção servia como moeda de troca onde entregava suas sacas de feijão por bens de consumo imediato, geralmente produtos alimentícios.

Um ponto que merece destaque se refere aos objetivos do PRONAF, no qual podemos perceber, de acordo com os entrevistados, que não estão sendo exercidos, pois, sete dos entrevistados disseram que o PRONAF não viabiliza infraestrutura apropriada à realização das atividades agrícolas ou que gere melhoria substancial no desempenho produtivo da família. Enquanto isso, os 09 entrevistados afirmaram que o programa não eleva o nível de profissionalização dos agricultores, dificultando o acesso às tecnologias. Partindo dessa ideia, entendemos que essa carência de profissionalização e dificuldade no acesso às novas tecnologias está relacionada à insuficiência ou ineficácia do acompanhamento e/ou assistência técnica dos projetos produtivos.

Quatro dos entrevistados alegam que o PRONAF estimula a comercialização da produção, enquanto que cinco deles acreditam que isso não acontece. Percebemos que os quatro entrevistados que atestam o estímulo, por parte do PRONAF, para a realização da comercialização, essa ocorre porque, para o banco (financiador do PRONAF), a venda da produção seria um grande auxílio para a quitação da dívida. No entanto, entendemos esse incentivo à comercialização por parte do PRONAF como uma forma de integralizar os agricultores no mercado capitalista.

Uma informação importante que verificamos, por via das entrevistas, é que esses agricultores assentados possuem o objetivo de quitarem a dívida do PRONAF, principalmente por meio da comercialização de cabeças de gado. Mas, nesse contexto, surge uma questão, a qual nos preocupa: como esses agricultores podem confiar na criação de gado para pagarem sua dívida, se nos últimos anos as chuvas não têm sido favoráveis e esses mesmos agricultores perderam parcialmente ou até mesmo totalmente seu gado? 
Uma experiência do PRONAF "A" no Alto Oeste Potiguar: o assentamento Sítio Coito

Com isso, nos questionamos como esses agricultores vão conseguir pagar essa dívida do PRONAF junto ao banco. O fato é que os próprios agricultores ainda estão sem saber como irão pagar essa dívida, porque eles ainda se encontram no período de carência e não começaram a pagar suas parcelas anuais. Certamente, quando terminar o período e não haver a quitação do financiamento, a instituição financeira deverá procurar os agricultores para fazer uma negociação e ampliar o prazo de pagamento, o que é comum nesta relação entre as instituições financeiras e o agricultor.

Esse período de carência se baseia em um recorte temporal em que o banco não exige o pagamento das parcelas, Neste caso, os assentados tiveram um período de carência de cinco anos. Só começarão a pagar no ano de 2018 e por isso ainda não tiveram conhecimento do total a ser pago em cada parcela.

No caso da assistência técnica, apenas dois disseram que recebem algum tipo de ajuda cedida pela EMATER, que ajuda na elaboração do projeto PRONAF, embora isso aconteça de forma bastante incipiente, uma vez que, os próprios agricultores são os que procuram informação ou assistência na sede desse órgão, de acordo com as suas necessidades. Dessa forma, os outros sete entrevistados disseram que não recebem nenhuma assistência, posto que nenhum representante do Estado ou profissional a este serviço frequenta regularmente o assentamento. Porquanto, subentendemos que existe assistência técnica, só que, devido ao fato de não ocorrer de forma sistemática e regularmente, acaba sendo ignorada pelos agricultores.

Partindo do pressuposto de que a seca gera dificuldades sociais que se refletem em vários aspectos, destacamos a falta de água, a dificuldade no desenvolvimento da agricultura, bem como da criação de animais como os mais impactantes. Os entrevistados da pesquisa destacaram esses mesmos problemas, dando destaque maior para a falta de alimento para o gado. No caso dos agricultores deste assentamento, percebemos que eles não elencam a falta de água para o consumo e nem para a criação de gado como a problemática mais grave, pois eles possuem um pequeno açude e um cacimbão que estão à disposição de todos os integrantes do assentamento para que possam dar de beber aos seus animais; além disso, as cisternas de placa têm abastecido as casas com água potável, que são voltadas para o consumo humano. Deste modo, o principal problema destacado pelos agricultores foi, por unanimidade, a dificuldade de alimento para o gado, isso porque a falta ou insuficiência de chuvas não faz brotar bons pastos. Além disso, os custos para se comprar alimentos alternativos como a torta de algodão (subproduto da extração do óleo contido no grão do algodão) ou "resídio", por exemplo, são muito altos e as famílias não possuem condição financeira para comprar esse produto, gerando assim uma redução 
considerável e até mesmo total na quantidade de cabeças de gado nos períodos de estiagem.

Desta forma, o assentamento possui quatro cacimbões, sendo que um deles (figura 04), como já foi escrito, serve para a utilização de todos os agricultores beneficiados, enquanto que os demais cacimbões são privados, sendo construídos com recursos individuais próprios. Em relação aos açudes, a situação é a mesma, o assentamento possui dois reservatórios, um é para a utilização coletiva dos assentados e o outro, que está em processo final de construção (figura 5), mas ainda não têm capacidade de fornecer água, terá caráter privado.

No entanto, o reservatório existente, utilizado pela coletividade, embora seja pequeno, torna-se suficiente para abastecer, entre outras coisas, a produção agrícola, a criação de gado e as atividades diárias das respectivas residências, como: banho, lavagem de roupa, de louças, da casa etc. Além disso, o assentamento contêm quatro cisternas de placa, que têm a função de abastecer o consumo humano. A partir disso, entendemos que os agricultores possuem água para o consumo humano através das cisternas de placa e água para dar de beber aos animais, por meio do reservatório e do cacimbão.

Figura 4: Cacimbão coletivo entre os assentados.

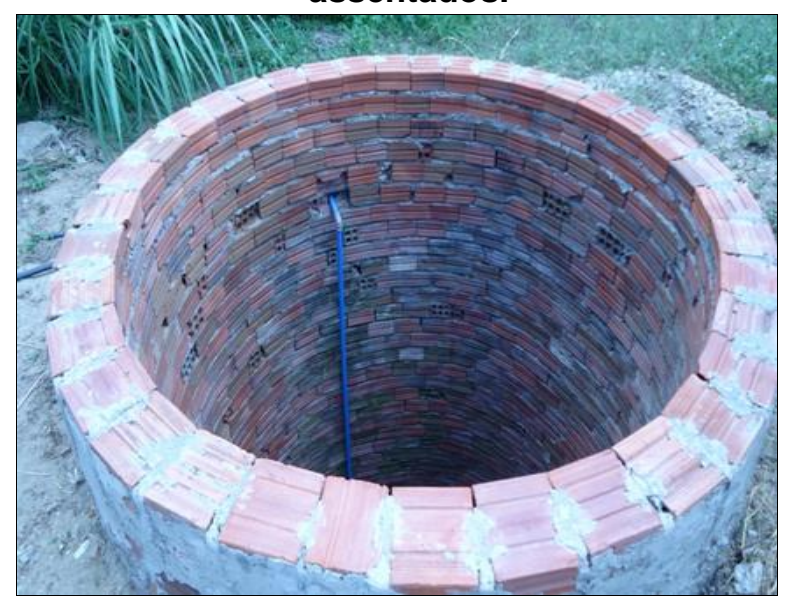

Autoria: Alessandra H. do Nascimento, nov., 2015
Figura 5: Construção do segundo reservatório

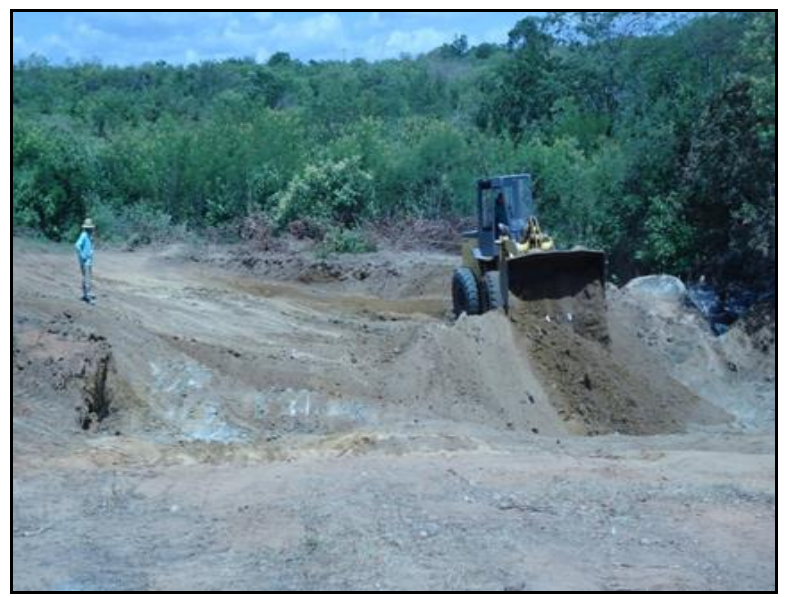

Autoria: Alessandra H. do Nascimento, nov. 2015.

Torna-se indispensável dizer que os agricultores não se utilizam de irrigação para regar plantações, pois, segundo eles, os custos a serem pagos pela energia elétrica são altos e a compra de mecanismos como motor, canos e aspersores, entre outros, também custam um elevado valor monetário.

No que se refere à importância assumida pelo PRONAF no dia a dia dos agricultores, constatamos, por meio das entrevistas, que este programa possui papel indispensável, já que esta linha de crédito é revestida de ações governamentais, no qual o financiamento cedido apresenta baixas taxas de juros, oscilando entre 0,5 e $4,5 \%$ ao ano, permitindo, 
Uma experiência do PRONAF "A" no Alto Oeste Potiguar: o assentamento Sítio Coito

deste modo, que o agricultor utilize tais recursos financeiros no que considerar necessário, como, por exemplo, para a compra de utensílios agrícolas destinados à produção. Com isso, todos os entrevistados consideram o PRONAF importante, justamente por essa justificativa citada pois, com os juros baixos, os agricultores encontram mais facilidade e tempo para planejarem e organizarem seu orçamento, para que, posteriormente, possam pagar as respectivas parcelas anuais.

\section{CONSIDERAÇÕES FINAIS}

A partir dessa análise da participação do PRONAF no assentamento do Sítio Coito em Marcelino Vieira tornou-se possível fazer alguns apontamentos referentes à implantação deste Programa no espaço rural do município.

Primeiramente, entendemos que este Programa não tem atuado da forma que deveria no assentamento do sítio Coito, pois os principais objetivos do PRONAF não se fazem cumprir na realidade. O primeiro objetivo do Programa, por exemplo, tem em vista fortalecer a agricultura familiar, mediante ajuda técnica e financeira, contribuindo para o desenvolvimento rural sustentável. Só que, na verdade, constatamos por intermédio da pesquisa que esses agricultores não recebem assistência técnica do órgão estadual responsável, que é a SEARA-RN e, com isso, o possível desenvolvimento rural sustentável também não acontece. Já o segundo objetivo consiste em fortalecer a aptidão produtiva da agricultura familiar, mas como essa aptidão produtiva poderá acontecer, sem que os agricultores tenham chuvas para produzir; recursos financeiros para investir em irrigação, por exemplo; assistência técnica que os oriente o quê, como e quando produzir; entre muitas outras questões? O terceiro e quarto objetivos se baseiam na colaboração para a geração de emprego e renda nas áreas rurais e aquilatar a qualidade de vida dos agricultores familiares. Mas o que registramos de fato não condiz com esses objetivos, pois a maioria dos assentados não reside no assentamento, justamente pela falta de emprego e renda para sustentar a família, uma vez que a renda oriunda da agricultura é mínima e insuficiente, até mesmo para o consumo da unidade familiar. Além disso, como que se pretende melhorar a vida dos agricultores assentados, se os mesmos não possuem acesso a serviços básicos de saúde e educação? Estes são indispensáveis quando se fala em qualidade de vida e agentes contribuintes para a fixação no campo.

O discurso do MDA articula que o Programa contribui para as transformações e avanços no espaço agrário nacional, possibilitando uma maior democratização do acesso ao crédito e a visibilidade social dos agricultores. No entanto, entendemos que nem tudo que está na teoria acontece na realidade, pois existem ineficiências neste Programa que desviam as metas e os objetivos. Em linhas gerais, compreendemos que os agricultores 
assentados necessitam, entre outras coisas, de condições mínimas de sobrevivência para que possam se fixar efetivamente no campo. Assim, as melhorias que necessitam surgir não devem estar pautadas exclusivamente na produção, uma vez que se deve investir com muito mais responsabilidade e coerência na questão social, implementando políticas, planos e programas governamentais que atuem em problemas como a seca, a dificuldade de acesso aos serviços básicos ligados à saúde e educação, o analfabetismo e a baixa qualificação profissional dos agricultores assentados, o que, por sua vez, poderia gerar um aumento na renda da família, além de conhecimento para passar a ter maior cuidado com a natureza e seus recursos.

\section{REFERÊNCIAS}

AZEVEDO, F. F. de; PESSOA, V. L. S. O Programa Nacional de Fortalecimento da Agricultura Familiar no Brasil: uma análise sobre a distribuição regional e setorial dos recursos. Soc. \& Nat. Uberlândia, ano 23, n 3, p. 483-496, set/dez. 2011.

. O Programa Nacional de Fortalecimento da Agricultura Familiar e as transformações da Agropecuária no Rio Grande do Norte: uma análise do período de 1995-2005. In: CHELOTTI, M. C.; MATOS, P. F. de; SANTOS, J. C. dos; SOUZA, M. M. O. de (Orgs.). Geografia Agrária e diversidades territoriais no campo brasileiro. Uberlândia (MG): Assis, 2012. p. 133-160.

COSTA, M. J. Uma leitura geográfica da Reforma Agrária Potiguar. Dissertação (Mestrado em Geografia). Programa de Pós-graduação e Pesquisa em Geografia, Universidade Federal do Rio Grande do Norte, Natal, 2005.

FELÍCIO, M. J. A conflitualidade dos paradigmas da questão agrária e do capitalismo agrário a partir dos Conceitos de agricultor familiar e de camponês. CAMPO-TERRITÓRIO: revista de geografia agrária, v. 1, n. 2, p. 14-30, agosto. 2006.

FERNANDES, B. M. A questão agrária em sua nova configuração socioeconômica, política e territorial. In: CASTRO, Iná Elias de. et al (Orgs.). Redescobrindo o Brasil: 500 anos depois. Rio de Janeiro: Bertrand Brasil, 1999. p. 223-231.

Espaços agrários de inclusão e exclusão social: novas configurações do campo brasileiro. AGRÁRIA, № 1, pp. 16-36, 2004.

IBGE - INSTITUTO BRASILEIRO DE GEOGRAFIA E ESTATÍSTICA. Divisão Regional do Brasil em mesorregiões e microrregiões geográficas. Rio de Janeiro: IBGE, v.1, 1990. $\overline{\text { abr. } 2015 .}$

Censo Demográfico 2010. Disponível em: http://www.ibge.gov.br. Acesso em 06

Evolução da divisão territorial do Brasil 1872-2010. Dados populacionais e territoriais. Memoria Institucional. 17. Rio de Janeiro: IBGE, 2011.

Glossário dos termos genéricos dos nomes geográficos utilizado no mapeamento sistemático do Brasil. v. 2. Rio de Janeiro, 2015.

IDEMA - Instituto do Desenvolvimento Sustentável e Meio Ambiente do Rio Grande do Norte. Anuário Estatístico do Rio Grande do Norte 2014. Natal: IDEMA, 2014.

MDA - MINISTÉRIO DO DESENVOLVIMENTO AGRÁRIO. Disponível em: http://www.mda.gov.br/. Acesso em 02 jun. 2015. 
SCHNEIDER, S.; MATTEI, L.; CAZELLA, A. A. Histórico, Caracterização e Dinâmica Recente do PRONAF - Programa Nacional de Fortalecimento da Agricultura Familiar. In: SCHNEIDER, S.; SILVA, M. K.; MARQUES, P. E. M. (Orgs.). Políticas Públicas e Participação Social no Brasil Rural. Porto Alegre: UFRGS, 2004. p. 21-50.

SOUSA, E. G; FONSECA, M. B. Políticas Públicas voltadas ao homem do campo: o PRONAF em Bananeiras/PB. Trabalho de Conclusão de Curso (Graduação em Geografia) Departamento de Geografia, Universidade Federal da Paraíba, João Pessoa, 2012.

TEIXEIRA, E. C. Políticas Públicas - O Papel das Políticas Públicas. 2002 - AATR-BA. Disponível em: <http://www.escoladebicicleta.com.br/politicaspublicas.pdf. Acesso em 05 fev. 2015.

WANDERLEY, M. N. B. Agricultura familiar e campesinato: rupturas e continuidade. Estudos Sociedade e Agricultura, Rio de Janeiro, p. 42-62, n. 21, 2003.

\footnotetext{
${ }^{1}$ Graduada em Geografia (UERN), Professora da rede da educação do Estado do Rio Grande do Norte, Universidade do Estado do Rio Grande do Norte, Campus de Pau dos Ferros, Departamento de Geografia. Campus Universitário, BR-405, km 153, s.n. Arizona, CEP: 59.900-000. Pau dos Ferros, RN - Brasil. E-mail: alessa.holanda@hotmail.com.

${ }^{2}$ Graduação em Geografia (UFRN), Doutorado em Geografia (UECE), Professor do Departamento de Geografia da Universidade do Estado do Rio Grande do Norte, Campus de Pau dos Ferros, e do Programa de Pós-graduação em Planejamento e Dinâmicas Territoriais do Semiárido (PLANDITES), Universidade do Estado do Rio Grande do Norte, Campus de Pau dos Ferros, Departamento de Geografia. Campus Universitário, BR-405, km 153, s.n. Arizona, CEP: 59.900-000. Pau dos Ferros, RN - Brasil. E-mail: josueabezerra@gmail.com.

${ }^{3}$ Os municípios são: Água Nova, Alexandria, Almino Afonso, Antônio Martins, Coronel João Pessoa Doutor Severiano, Encanto, Francisco Dantas, Frutuoso Gomes, João Dias Jose da Penha, Lucrécia, Luís Gomes, Major Sales, Marcelino Vieira, Martins, Paraná, Pau dos Ferros, Pilões, Portalegre, Rafael Fernandes, Riacho da Cruz, Riacho de Santana, São Francisco do Oeste, São Miguel, Serrinha dos Pintos, Taboleiro Grande, Tenente Ananias, Umarizal, Venha-Ver e Viçosa.
} 